\title{
Cytokine-induced Neutrophil Chemoattractant Mediates Neutrophil Influx in Immune Complex Glomerulonephritis in Rat
}

\author{
Xiaobo Wu, Arthur J. Wittwer, “ Linda S. Carr, * Barbara A. Crippes, * Joseph E. DeLarco, * and James B. Lefkowith \\ Departments of Medicine and Molecular Biology and Pharmacology, Washington University School of Medicine, St. Louis, Missouri \\ 63110; and *Monsanto Corporate Research, Monsanto Company, St. Louis, Missouri 63167
}

\begin{abstract}
Chemokines are a family of cytokines whose participation in inflammation in vivo remains to be established. Using the rat model of anti-glomerular basement membrane (GBM) nephritis, we found that mRNA for the chemokine CINC (cytokine-induced neutrophil chemoattractant) was induced in the kidney, and the corresponding protein was elaborated by isolated inflamed glomeruli. Production of CINC by glomeruli was unafifected by complement- or leukocyte-depletion prior to disease induction. Cytokines which induce CINC expression in renal cells (TNF- $\alpha$ and $\mathrm{L}-1 \beta$ ) were also expressed in the kidney during glomerular inflammation. TNF- $\alpha$ production, unlike CINC, was complement and leukocyte dependent. In vivo administration of anti-CINC, but not anti-human I-8, IgG selectively attenuated the influx of PMNs into the glomerulus and commensurately diminished proteinuria. The participation of CINC was not tissue-specific: anti-CINC IgG also diminished the influx of PMNs in dermal immune complex inflammation. In sum, we propose that glomerular immune complex deposition/complement activation leads to cytokine production which results in CINC expression by endogenous glomerular cells. The CINC produced plays a contributory role in the influx of PMNs into the glomerulus in the context of the activation of other inflammatory mediators. These results suggest a potential role for CINC homologues, $\mathrm{L}-8$ and the GRO family of chemokines, in human immune complexmediated disease. (J. Clin. Invest. 1994. 94:337-344.) Key words: chemokine - nephritis - immune complex • CINC $・$ IL-8
\end{abstract}

\section{Introduction}

Leukocyte migration from the blood into tissue in the context of inflammation is a complex phenomenon representing the integration of chemoattraction, endothelial adhesion, and transendothelial migration. There has been a veritable explosion of information regarding these processes over the past decade with the discovery of several families of adhesion molecules and pro-inflammatory cytokines. Part of this evolution of knowledge

Address correspondence to James B. Lefkowith, M.D., Box 8045, Division of Rheumatology, Washington University School of Medicine, St. Louis, MO 63110.

Received for publication 13 September 1993 and in revised form 16 March 1994.

J. Clin. Invest.

(c) The American Society for Clinical Investigation, Inc. 0021-9738/94/07/0337/08 \$2.00

Volume 94, July 1994, 337-344 has included the discovery of a large group of cytokines which display a variety of proinflammatory properties referred to as chemokines (for review see references 1 and 2). The chemokines are a family of polypeptides with four conserved cysteine residues which form two disulfide bonds. This family can thus be subdivided into two large groups depending on whether or not there is an intervening amino acid between the first two cysteines yielding the CXC and $\mathrm{CC}$ (or $\alpha$ and $\beta$ ) subgroups, respectively.

The principal biologic property of chemokines is their ability to attract and activate leukocytes in vitro, with the distinction between the CXC and CC subgroups being their target cell (1, $2)$. The CXC chemokines, of which $\mathrm{IL-8}$ is the most wellknown member, are active principally towards PMNs; whereas, the CC chemokines are relatively specific for monocyte/macrophages. However, as with most cytokines, additional work has suggested that these mediators may have pleotrophic effects $(1-4)$. Very little is known, in fact, about the participation of the chemokines in inflammation in vivo, and studies have suggested that these cytokines may not necessarily be proinflammatory in all circumstances $(5,6)$.

In an effort to understand the potential role of CXC chemokines in inflammation, we recently addressed whether the mediator cytokine-induced neutrophil chemoattractant (CINC) ${ }^{1}$ might play a role in immune complex-mediated inflammation using the rat model of anti-glomerular basement membrane (GBM) nephritis (i.e., nephrotoxic nephritis). This model of glomerular inflammation is induced by a polyclonal anti-GBM antibody and much of the acute phase injury to the glomerulus is mediated by PMNs $(7,8)$. We chose to focus on this particular member of the CXC family for several reasons: CINC has been shown to be active as a neutrophil chemoattractant in vitro and in vivo $(9,10)$; the potential of renal cells to make CINC in response to the cytokines TNF- $\alpha$ and $I L-1 \beta$ has been established $(11,12)$; and, both TNF- $\alpha$ and IL- $1 \beta$ have been implicated in the pathogenesis of immune complex glomerulonephritis (13-17).

The results we obtained suggest an important role for chemokines in mediating leukocyte migration in vivo. Moreover, the data provide for an understanding of the molecular mechanisms underlying chemokine synthesis in vivo, and the relative role of chemokines in the cascade of events which mediate PMN migration into tissue during immune complex-mediated inflammation.

\section{Methods}

Induction of immune complex injury. Anti-GBM nephritis was induced by the injection of a rabbit anti-rat GBM antibody, the preparation

1. Abbreviations used in this paper: CINC, cytokine-induced neutrophil chemoattractant; CVF, cobra venom factor; GBM, glomerular basement membrane; GAPDH, glutaraldehyde phosphate dehydrogenase; MPO, myeloperoxidase. 
of which has been described previously (18). Antiserum preparations contained no detectable endotoxin $(<0.1 \mathrm{U} / \mathrm{ml})$. Nephritis was induced with a dose of $0.5 \mathrm{ml} / 100 \mathrm{~g}$ body weight by intravenous injection in Lewis rats (Charles River, Wilmington, MA). Renal function was then assessed by collecting urine for $24 \mathrm{~h}$ using a metabolic cage and determining proteinuria by a microspectrophotometric method with an assay system from Bio-Rad laboratories (Richmond, CA). Kidneys were harvested for PCR analysis at 1,2 , or $3 \mathrm{~h}$ after disease induction and flash frozen in liquid nitrogen. Kidneys were also harvested for the isolation of glomeruli (at 3 and $24 \mathrm{~h}$ after disease induction) or to obtain tissue for immunocytochemistry or standard histology (at $3 \mathrm{~h}$ after disease induction). Isolated glomeruli were used for either in vitro incubation or were dissociated into a single cell preparation for leukocyte quantification (see below).

Dermal immune complex injury was induced with the same immune complex system as the kidney disease. GBM/anti-GBM immune complexes were formed by mixing equal volumes of anti-GBM antiserum and a $2 \mathrm{mg} / \mathrm{ml}$ suspension of GBM in PBS (incubated at $37^{\circ} \mathrm{C}$ for 30 min). Immune complex injury was then induced by the subcutaneous injection of $200 \mu \mathrm{l}$ of immune complexes which yielded a near maximal injury (data not shown). After $8 \mathrm{~h}$ animals were killed and a 6-mm punch biopsy through the epidermis/dermis (ending in the pre-muscular fascia) was obtained and weighed. Histology was assessed on formalinfixed sections stained with hematoxylin/eosin. Tissue myeloperoxidase (MPO) was assessed in the remaining tissue using a published protocol and normalized for tissue weight (19).

In vivo manipulation of inflammation. To assess the role of CINC in vivo, an affinity-purified preparation of goat anti-rat CINC was used, the preparation and characterization of which has been recently published (20). This antibody does not react significantly with human IL-8 or rat MCP-1 and reacts with the human GRO family of polypeptides with substantially less affinity ( $\sim 60$-fold lower) $(20,21)$. Additionally, reactivity with rat GRO- $\beta$ (known also as MIP-2 (22) is $<0.01 \%$ by ELISA (data not shown). Animals were treated with $1 \mathrm{mg}$ of affinity-purified goat anti-CINC IgG $1 \mathrm{~h}$ before, and coincident with, disease induction injected intravenously. Nephritic controls were given a corresponding amount of purified nonbinding goat IgG. Alternatively, the role of IL-8 was determined by the administration of a monoclonal against human IL-8 (DM/C7; provided by M. Bolanowski, Monsanto Co., St. Louis, MO) or an isotype-matched control antibody. DM/C7 does not cross-react with CINC $(20,21)$. IgG preparations contained $\leq 0.1 \mathrm{U} / \mathrm{ml}$ of endotoxin.

To examine the roles of complement and leukocytes in cytokine expression, animals were either decomplemented with cobra venom factor (CVF) or irradiated prior to disease induction. Animals were decomplemented by administering $10 \mathrm{U} / 100 \mathrm{~g}$ body weight of CVF (Diamedix, Miami, FL) intraperitoneally 48,24 , and $12 \mathrm{~h}$ before the injection of anti-GBM antibody as previously detailed (18). This protocol depresses complement throughout the first $24 \mathrm{~h}$ after disease induction to $<20 \%$ of control, completely inhibits the influx of PMNs into the glomerulus, and prevents proteinuria (18; and data not shown). Animals were leukocyte depleted by exposure to 1,000 rads under anesthesia $72 \mathrm{~h}$ prior to disease induction. This protocol depletes circulating and resident glomerular leukocytes by $>90 \%$ ( 18 ; and data not shown).

Glomerular isolation, incubation, and leukocyte quantification. Glomeruli were isolated from saline-perfused kidneys using a sieving protocol described previously (18). Glomeruli were then used for either ex vivo incubation or dissociated into a single cell preparation for leukocyte quantitation. These preparations of glomeruli are free of circulating leukocytes (18).

Glomeruli were incubated in vitro as previously detailed (18). Briefly, after two 10-min stabilization periods, glomeruli were incubated for $10 \mathrm{~min}$ (for CINC) or $30 \mathrm{~min}$ ( for TNF- $\alpha$ ). Glomerular supernatants were then assayed for cytokine production using specific ELISAs for either CINC (20) or TNF- $\alpha$ (Genzyme Corp., Cambridge, MA). Cytokine production was normalized for both glomerular number and time of incubation, and is expressed as a production rate (amol/10 ${ }^{3}$ glomeruli/min). To determine approximate intraglomerular concentra- tions, an average glomerular radius of $60 \mu \mathrm{m}$ was used (ca. $1 \mu \mathrm{l} / 10^{3}$ glomeruli) (23). Intraglomerular concentrations were then estimated by dividing total production for $30 \mathrm{~min}$ by the glomerular volume.

To perform glomerular leukocyte counts, $20-30 \times 10^{3}$ glomeruli from a single animal were dissociated into a single cell suspension by means of an enzymatic protocol and stained using an immunoperoxidase method previously published (24). Briefly, cytospin preparations of leukocytes were stained with an anti-rat leukocyte common antigen (CD45; Chemicon, Temecula, CA) antibody, washed, and then exposed to a rabbit anti-mouse antibody conjugated to horseradish peroxidase (Bio-Rad Laboratories). Cells were again washed, and bound antibody was visualized with diaminobenzidine (Sigma Chemical Co.). Hematoxylin was used as a counterstain (EM Diagnostic Systems, Inc., Gibbstown, NJ). Positively labeled cells were visualized by light microscopy and categorized by nuclear morphology. The percentage of positive cells (or leukocyte subsets) were multiplied by the total cell yield per glomerulus to derive the number of leukocytes (or leukocyte subsets) per glomerulus. This method correlates well with other methods of leukocyte quantification such as in situ staining (25).

Determination of cytokine expression in kidney by PCR. RNA was extracted from kidney using guanidinium thiocyanate and isolated by ultracentrifugation on a $\mathrm{CsCl}$ gradient using published methods (26). Reverse transcriptase PCR for CINC, IL- $\alpha$, and GAPDH was then performed on $1 \mu \mathrm{g}$ of RNA for 40 cycles using the following sequence: $94^{\circ} \mathrm{C}, 30 \mathrm{~s} ; 50^{\circ} \mathrm{C}, 30 \mathrm{~s} ; 72^{\circ} \mathrm{C}, 30 \mathrm{~s}$. Primers used for CINC and glutaraldehyde phosphate dehydrogenase (GAPDH) expression were HMC3 and HMC20, and JZ138 and JZ139, respectively (27). Primers for IL-1 $\alpha$ were GATCGTCAAGCAGGAGTTCA (sense) and TGGGAAAGCTGCGGATGTGA (antisense). Because the rat sequences for IL- $1 \beta$ and TNF- $\alpha$ are not available, we used the mouse primers which were purchased from Stratagene Corp. (La Jolla, CA). Reverse transcriptase PCR for IL- $1 \beta$ and TNF- $\alpha$ were performed on $1 \mu \mathrm{g}$ of RNA using the manufacturer's recommended sequence (IL- $1 \beta, 30$ cycles; TNF- $\alpha, 35$ cycles).

Both normal and nephritic kidneys were examined. As an additional specificity control, we also examined the expression of cytokines by PCR in RNA from NRK49F cells (normal rat kidney fibroblasts) without or with IL- $1 \beta$ stimulation.

Immunocytochemistry of renal tissue. IL- $1 \beta$ expression was assessed by immunocytochemistry on fresh frozen kidney tissue. Tissue sections were blocked with PBS with $10 \%$ horse serum (PBSS) and then incubated with hamster monoclonal anti-mouse $\mathrm{IL}-1 \beta$ (Genzyme Corp.) at a concentration of $50 \mu \mathrm{g} / \mathrm{ml}$ in PBSS. A biotinylated goat anti-hamster antibody was used as the secondary reagent (Southern Biotechnology, Birmingham, AL) followed by avidin-biotin-horseradish peroxidase complexes (Vector Labs, Burlingame, CA). Staining was performed using diaminobenzidine with a hematoxylin counterstain as with glomerular cell dissociates above. Recombinant mouse IL-1 $\beta$ (provided by Dr. David Chaplin, Washington University, St. Louis, MO) was used in competitive binding experiments.

Statistical analysis. Statistical analysis was performed with the aid of STATA (Computing Resource Center, Los Angeles, CA). Values are expressed as means $\pm S E$. Comparisons between two groups were made with Student's $t$ test. Comparisons between multiple groups were made with ANOVA combined with Bonferroni's correction for multiple comparisons.

\section{Results}

CINC expression/production in nephritis. As early as $1 \mathrm{~h}$ after the injection of the anti-GBM antibody, we found that CINC mRNA was detectable in inflamed rat kidney by reverse transcriptase PCR whereas it was undetectable in normal kidney (Fig. 1). Induction of CINC was similarly observed in NRK49F cells exposed to IL-1 $\beta$ (Fig. 1). The induction of CINC mRNA was accompanied by the elaboration of CINC protein by inflamed glomeruli as detected in supernatants from glomeruli 


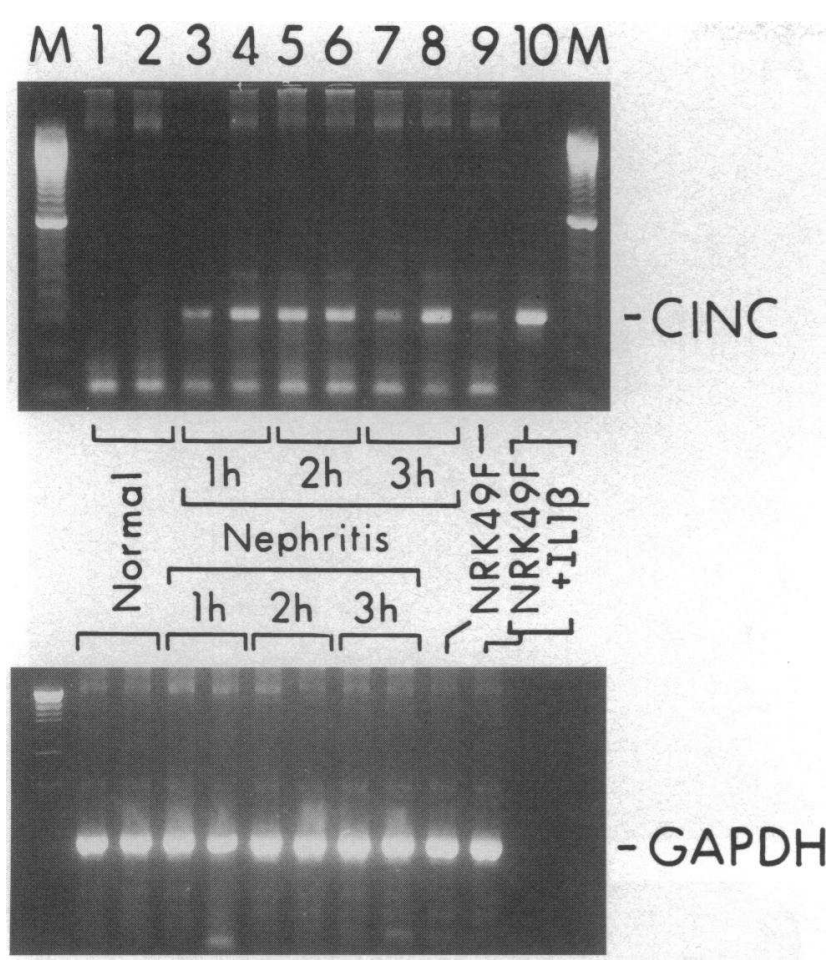

Figure 1. Induction of CINC during glomerular immune complex inflammation. The expression of CINC mRNA in the kidney of normal and nephritic rats was determined by PCR as detailed in Methods. Nephritic kidneys were removed 1, 2, or $3 \mathrm{~h}$ after disease induction. The top and bottom panels show the PCR results using CINC and GAPDH primers, respectively. Labels on the sides indicate the sizes of the expected products. Lanes 1 to 8 , analyses from individual rats (normal or with nephritis from 1-3 h). Lanes 9 and 10 , mRNA from NRK49F rat kidney fibroblasts without or with IL- $1 \beta$ stimulation as controls to show the induction of CINC.

isolated $3 \mathrm{~h}$ after disease induction and incubated in vitro (Fig. 2 ). CINC production in vitro was sufficient to produce an estimated glomerular concentration of $4 \mathrm{nM}$, a concentration which is chemotactic both in vitro and in vivo $(9,10)$.

Decomplementation of animals prior to the induction of nephritis, which abrogates the influx of PMNs into the glomerulus and prevents proteinuria (18; and data not shown), did not substantially diminish the elaboration of CINC by glomeruli (Fig. 2). Leukocyte depletion prior to disease induction also did not substantially attenuate in vitro production of CINC by glomeruli from nephritic animals isolated $3 \mathrm{~h}$ after disease induction (Fig. 2). Additionally, production of CINC by glomeruli isolated $24 \mathrm{~h}$ after disease induction, although modestly decreased relative to glomeruli isolated $3 \mathrm{~h}$ after disease induction (ca. 30\%), was still significantly increased relative to normal glomeruli (Fig. 2).

$T N F-\alpha$ and IL-1 expression/production in nephritis. Since CINC expression and production are induced by TNF- $\alpha$ and IL- $\beta$ in vitro $(11,12,20)$, and since these cytokines have been implicated in the pathogenesis of nephritis (13-17), we subsequently assessed for the production of these cytokines during nephritis. Recent work has shown that IL- $1 \beta$ and TNF$\alpha$ mRNA are expressed in nephritic glomeruli (17). We were able to corroborate these data by reverse transcriptase PCR,

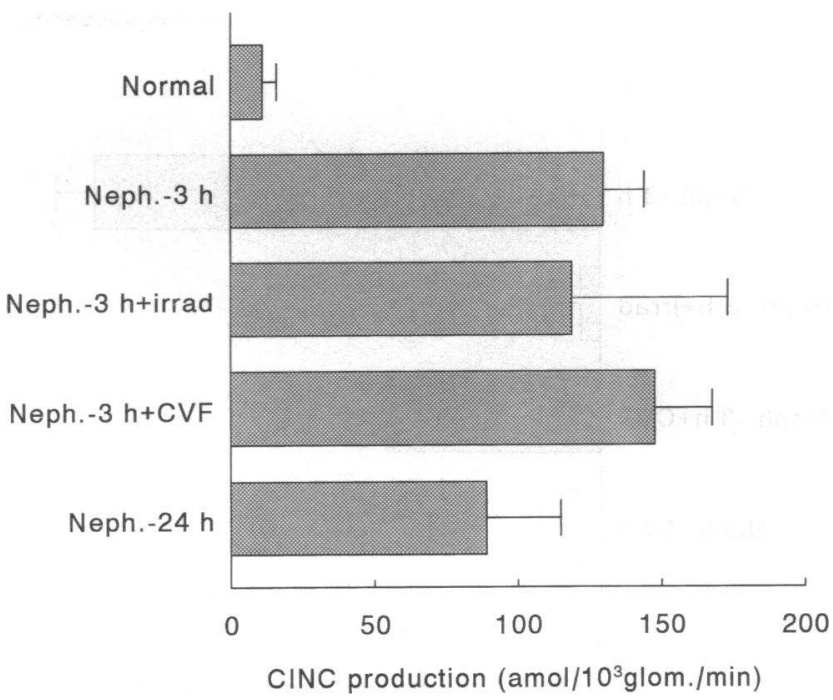

Figure 2. Production of CINC by isolated glomeruli. Glomeruli were isolated from normal rats and from nephritic, nephritic-decomplemented, and nephritic-leukocyte depleted rats $3 \mathrm{~h}$ after disease induction (Neph.-3 h, Neph.-3 $h+C V F$, and Neph.-3 $h+i r r a d$, respectively). Glomeruli were also isolated from nephritic rats $24 \mathrm{~h}$ after disease induction (Neph.-24 h). Glomeruli were then cultured ex vivo as detailed in Methods, and the resulting supernatants assayed by an ELISA specific for rat CINC. Results are expressed as a production rate normalized for number of glomeruli ( $\mathrm{amol} / 10^{3}$ glomeruli $/ \mathrm{min}$ ). $n=4,3,3$, 3,3 for the groups shown top to bottom. Comparison of normals to all other groups was statistically significant $(P<0.05)$.

although we found that IL- $1 \alpha$ mRNA was not substantially upregulated in nephritic kidneys (data not shown).

We confirmed the production of TNF- $\alpha$ by inflamed glomeruli removed $3 \mathrm{~h}$ after disease induction by measuring TNF- $\alpha$ content in the supernatants from ex vivo glomerular incubations (Fig. 3). The level of TNF- $\alpha$ production by inflamed glomeruli was sufficient to yield an estimated intraglomerular concentration of $0.8 \mathrm{nM}$. Normal glomeruli made no detectable TNF- $\alpha$ $\left(<0.3 \mathrm{amol} / 10^{3} \mathrm{glomeruli} / \mathrm{min}\right)$. TNF- $\alpha$ production, unlike CINC, was partly complement-dependent (Fig. 3). Decomplementation of animals prior to induction of nephritis suppressed TNF- $\alpha$ elaboration by $\sim 50 \% 3 \mathrm{~h}$ after disease induction. Also, unlike CINC production, TNF- $\alpha$ was largely dependent on the presence of leukocytes (Fig. 3). Leukocyte depletion decreased TNF- $\alpha$ production by inflamed glomeruli removed $3 \mathrm{~h}$ after disease induction by $>90 \%$. TNF- $\alpha$ production also was significantly lower $24 \mathrm{~h}$ after disease induction although it was still detectable (Fig. 3).

We were additionally able to validate the induction of IL- $1 \beta$ within the glomerulus, albeit qualitatively, by immunocytochemistry. As shown in Fig. 4 , IL- $1 \beta$ staining was apparent within inflamed glomeruli $3 \mathrm{~h}$ after disease induction, whereas expression by normal glomeruli was nil.

Biological significance of CINC in nephritis. To discern the contribution of CINC to the acute phase of glomerular inflammation, we next pretreated animals in vivo with affinity-purified polyclonal anti-CINC IgG (which blocks CINC functional activity in vitro) (20). Administration of this antibody significantly decreased glomerular inflammation by standard histology (Fig. 5). This difference was quantified by immunocytochemical analysis of dissociated glomerular cells. As shown in Fig. 


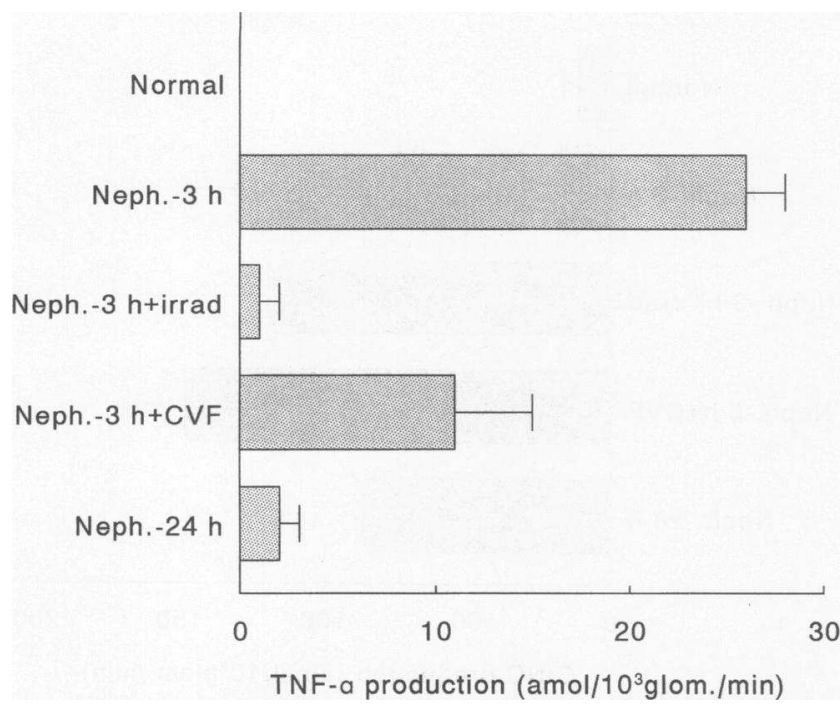

Figure 3. Production of TNF- $\alpha$ by isolated glomeruli. Glomeruli were isolated from normal rats and from nephritic, nephritic-decomplemented, and nephritic-leukocyte depleted rats $3 \mathrm{~h}$ after disease induction (Neph.-3 h, Neph.-3 $h+C V F$, and Neph.-3 $h+$ irrad, respectively). Glomeruli were also isolated from nephritic rats $24 \mathrm{~h}$ after disease induction (Neph.-24 h). Glomeruli were then cultured ex vivo, and the resulting supernatants assayed by an ELISA specific for TNF- $\alpha$. Results are expressed as a production rate normalized for glomerular number (amol $\left./ 10^{3} \mathrm{glomeruli} / \mathrm{min}\right) . n=3$ for all the groups shown. Comparison of nephritic rats to all the other groups was statistically significant ( $p$ $<0.05)$.

$6 \mathrm{~A}$, anti-CINC IgG decreased the influx of leukocytes into the glomerulus, principally via its effects on PMNs. Antibody administration did not affect the population of macrophages in the glomerulus at this time point. These cells represent a mixture of both the resident glomerular macrophages as well as the early influx of blood monocytes (28).

To determine whether this reduction in PMN influx was biologically significant, we also assessed the effects of the antiCINC IgG on the proteinuria which occurs during the first 24 $\mathrm{h}$ following disease induction. Proteinuria during this phase appears to be attributable mostly to the influx of PMNs with a smaller component $(<20 \%)$ attributable to complement activation (18). Administration of anti-CINC IgG reduced the acute proteinuria, commensurate to the reduction in PMN influx (Fig. $6 \mathrm{~B})$.

As an additional control we examined whether antibody to human IL- 8 had any effect on the acute phase of this model of inflammation. IL-8 has a similar spectrum of action to CINC and $\sim 50 \%$ homology in primary sequence (29). Although it is uncertain what the homologues to IL-8 are in sub-human species, recent studies have shown that monoclonal anti-human IL-8 IgGs with functional blocking activity decrease PMN influx in rat and rabbit models of acute inflammation $(21,30)$. However, we found that an anti-human IL-8 IgG (DM/C7) was ineffective in diminishing glomerular inflammation or proteinuria in anti-GBM nephritis. Glomerular leukocyte counts were $113 \pm 4$ and $117 \pm 9$ leukocytes/glomerulus in nephritic animals treated with an isotype-matched control monoclonal and DM/C7-treated nephritic animals, respectively ( $n=3$ for both, $P=$ NS $)$. No differences were noted in the observed numbers
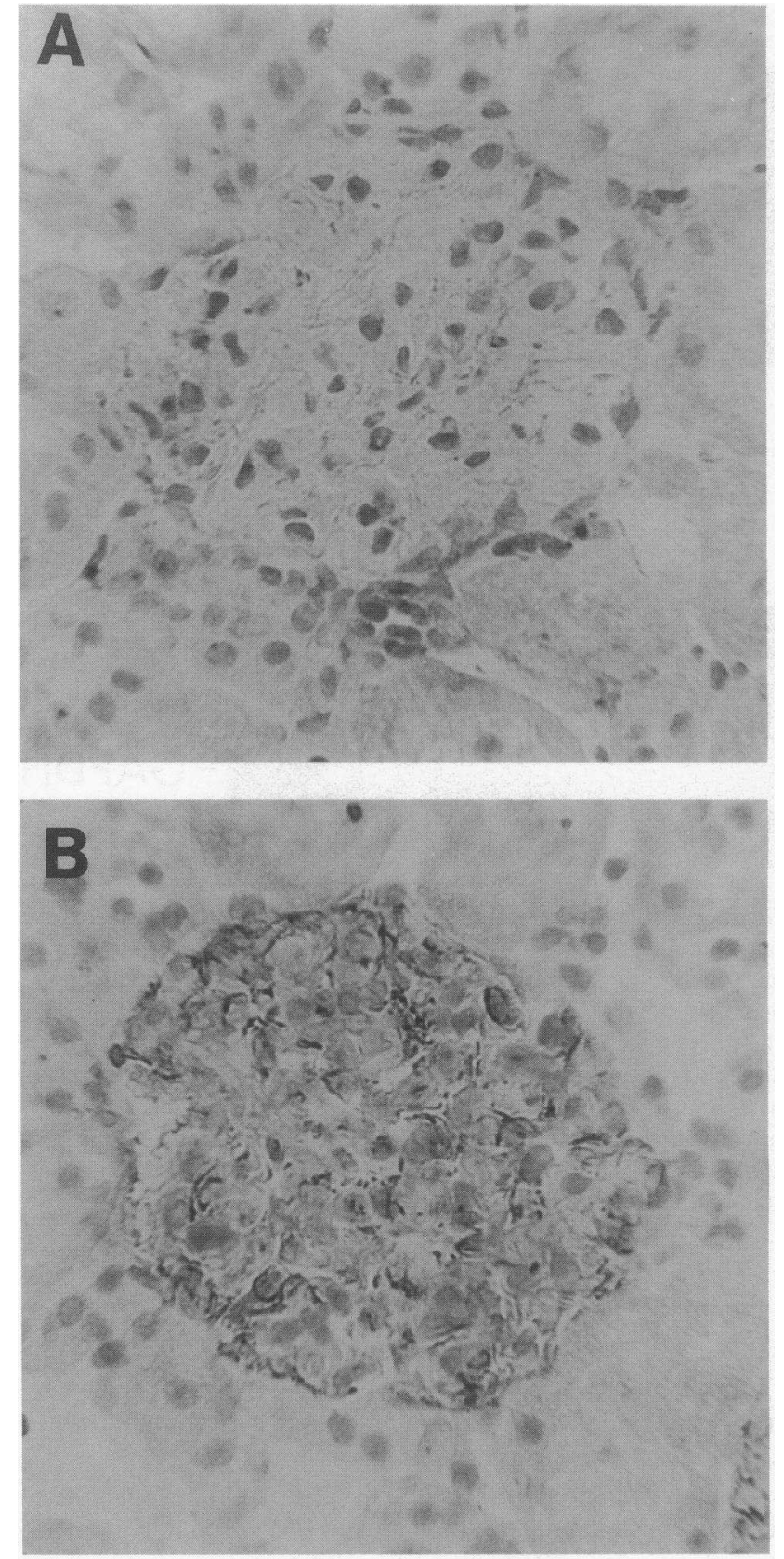

Figure 4. Immunocytochemical staining for IL- $1 \beta$ in nephritic glomeruli. Frozen sections from normal $(A)$ and nephritic kidneys removed 3 $\mathrm{h}$ after disease induction $(B)$ were analyzed for $\mathrm{IL}-1 \beta$ expression using a hamster anti-mouse IL- $1 \beta$ antibody as detailed in Methods. A representative experiment ( 1 of 3 ) is shown in which staining was evident only in inflamed glomeruli. No staining was noted in nephritic kidneys without primary antibody and staining was competitively inhibited by the inclusion of IL-1 $\beta 40 \mu \mathrm{g} / \mathrm{ml}$ with the primary antibody (not shown).

of PMNs or macrophages with the administration of DM/C7 either (data not shown). Proteinuria was $57 \pm 4$ and $87 \pm 25 \mathrm{mg}$ / $24 \mathrm{~h}$ in the two groups, respectively ( $n=5$ for both, $P=\mathrm{NS}$ ).

Relevance of CINC to dermal immune complex injury. To discern whether the participation of CINC in immune complex injury was specific to renal inflammation, we additionally examined the effect of anti-CINC IgG on immune complex-mediated 

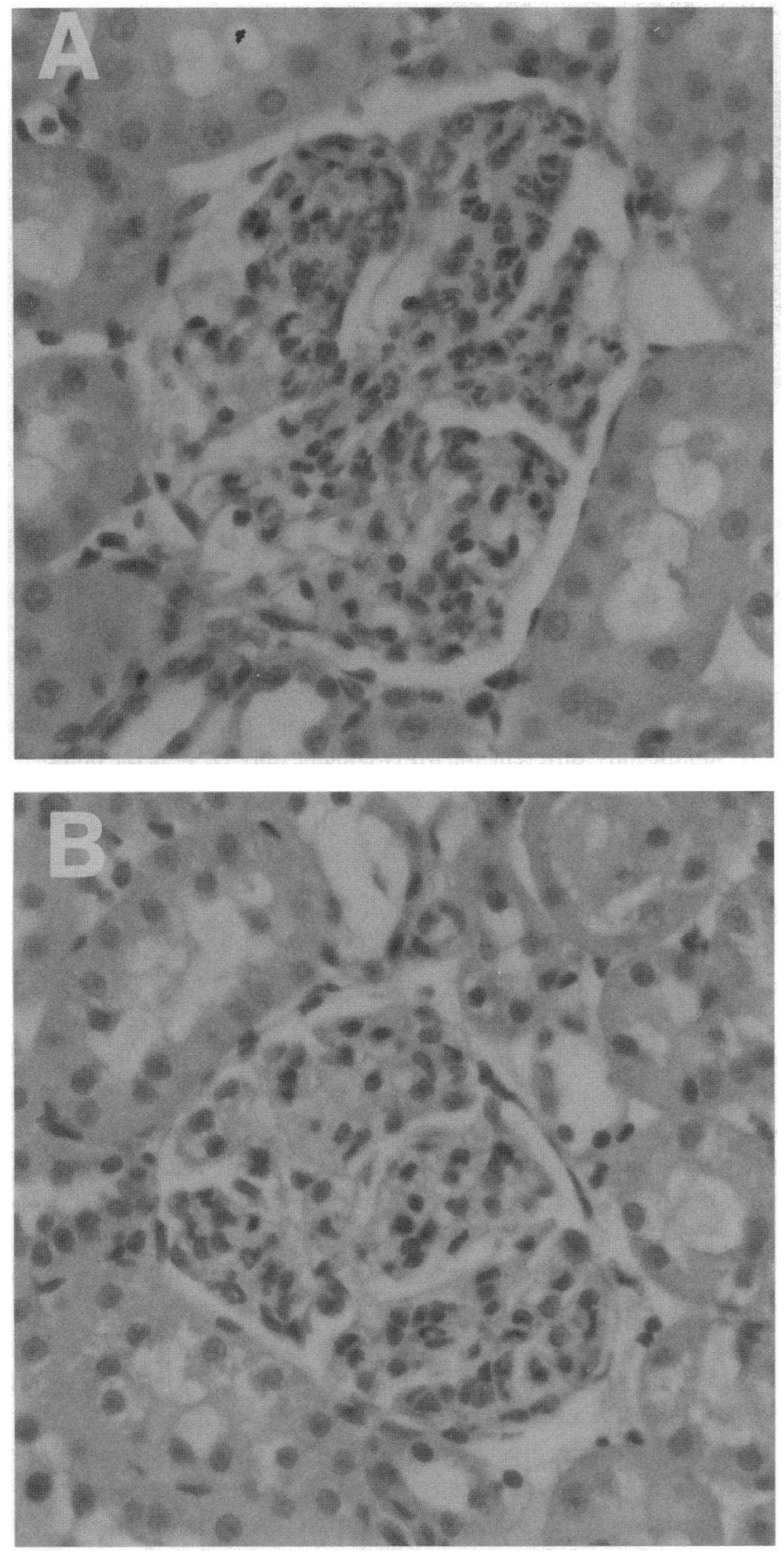

Figure 5. Effect of anti-CINC IgG on glomerular histology. Nephritis was induced in both control antibody-treated animals and animals pretreated with anti-CINC IgG. Renal tissue was then procured $3 \mathrm{~h}$ after disease induction and standard hematoxylin and eosin stained sections of formalin-fixed tissue prepared. Representative glomeruli from control antibody-treated and anti-CINC IgG-treated nephritic animals are shown ( $A$ and $B$, respectively, $\times 400$ ). Control antibody-treated animals $(A)$ showed a diffuse infiltrative/proliferative glomerulonephritis with a prominent component of PMNs. Anti-CINC IgG-pretreated nephritic animals exhibited a less diffuse inflammatory infiltrate and decreased numbers of PMNs $(B)$.

inflammation in the skin using the same immune complex system. As shown in Figs. 7 and 8, anti-CINC IgG significantly attenuated the influx of PMNs into the dermis in response to GBM/anti-GBM complexes as seen both at the level of light microscopy as well as with the more quantitative assessment using tissue MPO activity. In contrast to proteinuria in the above
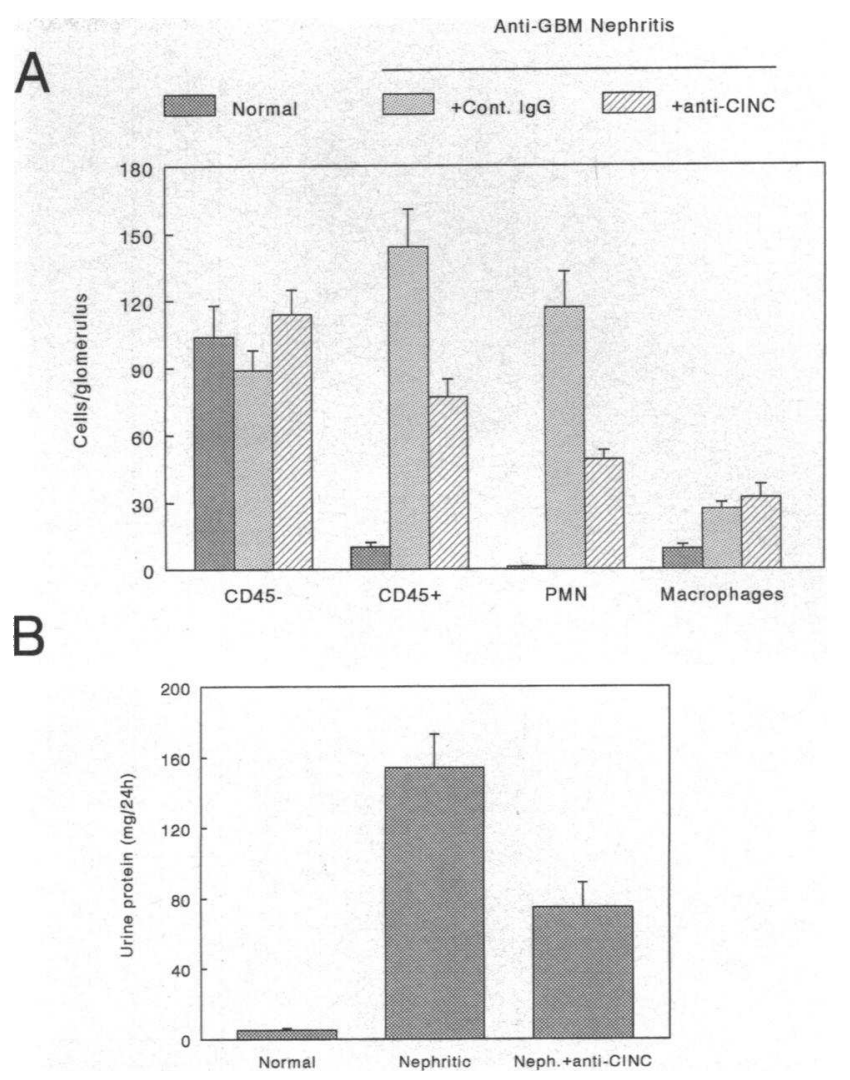

Figure 6. Effect of anti-CINC IgG on glomerular leukocytes and proteinuria. $(A)$ Glomeruli were isolated from animals with anti-GBM nephritis treated with nonbinding IgG and nephritic animals pre-treated with antiCINC IgG $3 \mathrm{~h}$ after disease induction. Normal glomeruli were also isolated. Glomerular leukocytes (CD45+ cells) and their subsets were then quantified in glomerular cell dissociates by immunocytochemistry/ nuclear morphology as detailed in Methods. The two groups of nephritic rats were significantly different for total leukocytes and PMNs $(n=7$ for both, $P<0.05$ ). CD45- cells represent mostly mesangial cells. $(B)$ Proteinuria was determined in 24-h urine collections from normal controls, animals with anti-GBM nephritis treated with nonbinding IgG, and nephritic animals pre-treated with anti-CINC IgG. The latter two groups were significantly different $(n=10$ for both, $P<0.05)$.

studies on nephritis, tissue edema was not affected by the administration of anti-CINC IgG either by morphology (in terms of dermal thickness, Fig. 7) or as determined by the increase in tissue weight (Fig. 8). These data corroborate previous observations that subcutaneously injected CINC mediates a transient influx of PMNs but not vascular leakage (9).

\section{Discussion}

Although much is known about the biochemistry and in vitro activity of chemokines, little is known about their biological function in vivo. This study provides compelling evidence for the participation of the chemokine, CINC, in a rat model of immune complex-mediated inflammation in vivo. Specifically, we have established that CINC mRNA is induced early on after induction of immune-mediated glomerulonephritis, that the corresponding protein is elaborated by isolated inflamed glomeruli in physiologically active concentrations, and that inhibition of CINC using a function-blocking antibody attenuates 

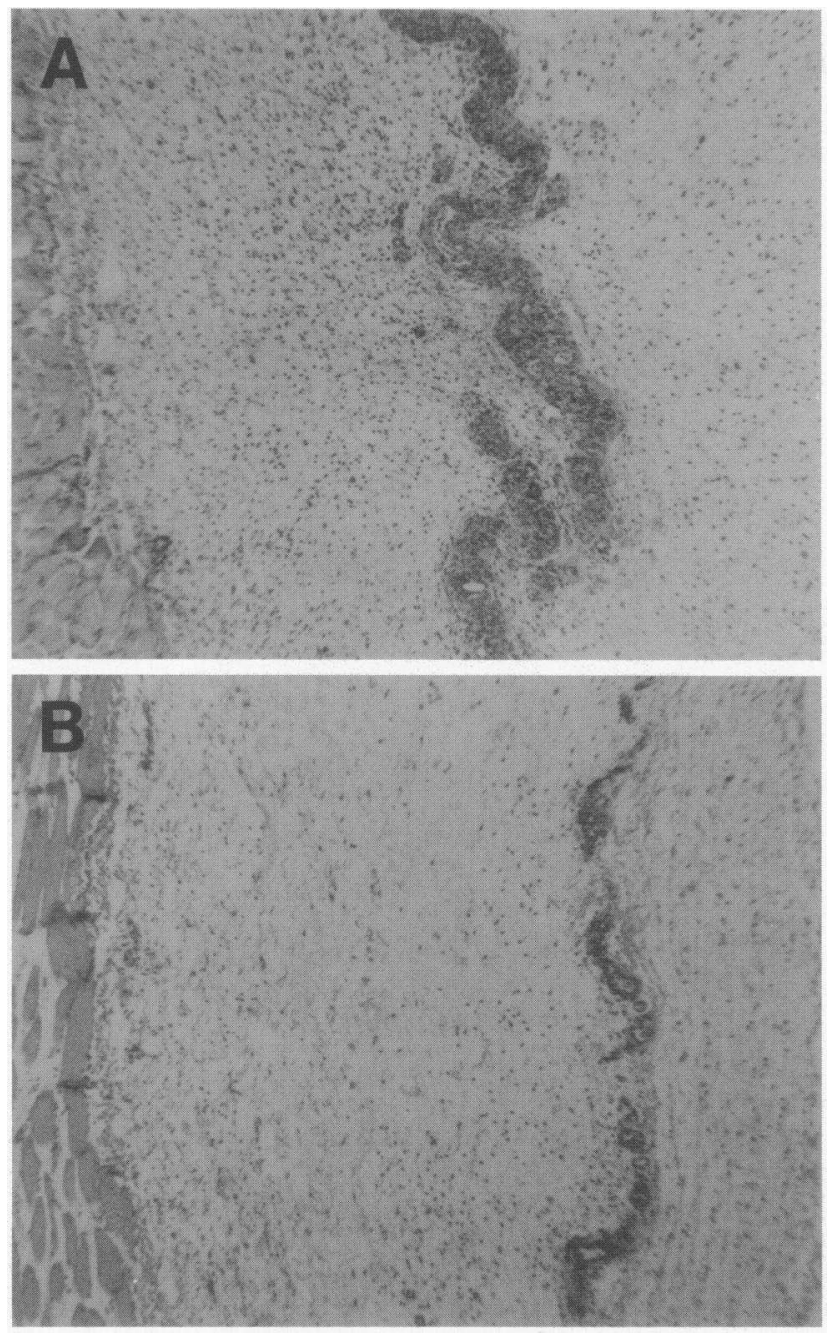

Figure 7. Effect of anti-CINC IgG on the histology of dermal immune complex inflammation. Dermal immune complex injury was induced as detailed in Methods. Representative dermal sections (obtained $8 \mathrm{~h}$ after induction of disease) from animals treated with control $\operatorname{IgG}(A)$ and animals pretreated with anti-CINC IgG $(B)$ are shown (both $\times 100$ ). Animals treated with control IgG evidenced an angiocentric inflammatory cell infiltrate which extended into the dermis and consisted mainly of neutrophils (dark nuclei within infiltrate were $>90 \%$ PMNs under higher power, not shown). Dermal edema was also apparent. Animals treated with anti-CINC IgG showed a much reduced neutrophil infiltrate but still exhibited dermal edema.

both the influx of PMNs into the inflammatory locus and the resulting glomerular damage.

As noted above, recent studies have suggested a role for an IL-8-like molecule in mediating the migration of PMNs in acute inflammation using anti-human IL-8 antibody in rats and rabbits $(21,30)$. It is unlikely, though, that our results can be attributed to the participation of an IL-8-like CINC homologue. We observed expression of both CINC mRNA and CINC protein, and the anti-CINC antibody used does not cross-react significantly with the human IL-8/GRO family of chemokines (the human homologues of CINC) (11) or rat GRO $\beta$. Although there are technical reasons that may explain the apparent discrepancies between these studies (e.g., differences in antibody administration, use of different antibodies, differences in in-

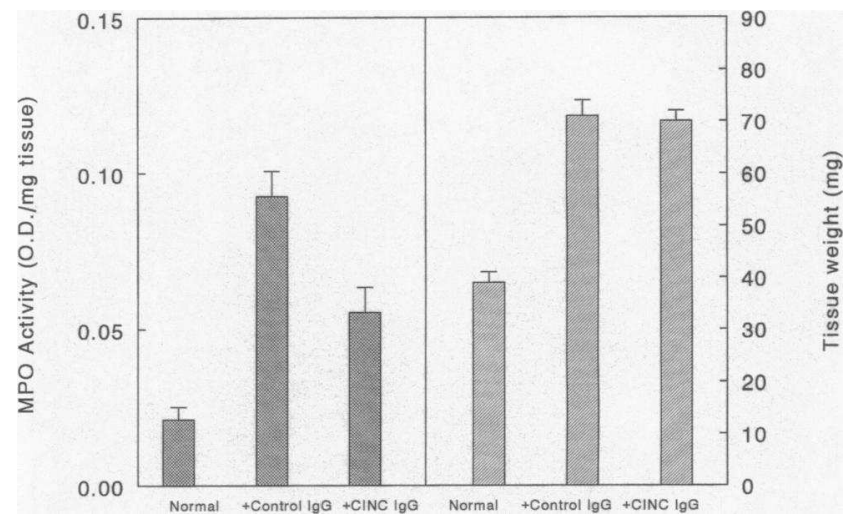

Figure 8. Effect of anti-CINC IgG on tissue MPO activity and edema in dermal immune complex inflammation. Tissue MPO content and weight was determined $8 \mathrm{~h}$ after the injection of immune complexes in animals pretreated with control IgG, and animals pretreated with antiCINC IgG in 6-mm punch biopsies of epidermis/dermis as detailed in Methods. Tissue MPO content and weight were also determined in 6mm punch biopsies of normal epidermis/dermis. The two former groups were significantly different for MPO content only ( $n=6$ for both, $P<0.05)$.

flammatory stimuli), resolution of these issues will ultimately depend on elucidation of the members of the CXC chemokines in sub-human species.

Regarding the specificity of the role of CINC in inflammation, the current data would suggest that the participation of CINC is not tissue-specific in that our anti-CINC antibody also blocked the influx of neutrophils in dermal immune complexmediated inflammation. Although our current data do not address the issue of stimulus-specificity, published work and observations by us in other models of inflammation suggest that CINC may participate in the migration of PMNs in response to multiple inflammatory stimuli (10) (Wittwer, A. J., L. S. Carr, and J. E. De Larco, manuscript submitted for publication). These data, in sum, suggest that the role of chemokines in mediating PMN trafficking may be a general one.

It is noteworthy from a pathophysiologic point of view that anti-CINC antibody attenuated proteinuria in our model of nephritis, whereas it had no effect on the generation of dermal edema in dermal immune complex-mediated inflammation. This apparent discrepancy likely reflects the difference in the generation of these two manifestations of tissue injury rather than a difference in the role of CINC. Proteinuria in anti-GBM nephritis is mediated largely via the activation of PMNs within the glomerulus and their production of reactive oxygen species or proteinases in situ $(7,8)$. In contrast, the generation of tissue edema in dermal immune complex injury results from the elaboration of vasoactive substances locally (such as $\mathrm{PGE}_{2}$ and peptidoleukotrienes) by resident tissue mast cells (31).

In addition to substantiating a role for CINC in mediating the trafficking of PMNs, data from the present work also provide insights into the molecular mechanisms underlying chemokine synthesis in vivo. As we noted, CINC expression and production were independent of the presence of complement. Thus, antibody/immune complex deposition per se appears sufficient for the expression of CINC. Moreover, the lack of an effect of either complement- or leukocyte-depletion on the expression of CINC suggests that CINC is produced exclusively by endoge- 
nous glomerular cells. In support of this latter conclusion, production of CINC by transformed kidney cells (epithelioid and mesenchymal) has been shown previously $(11,12,20)$, and we have observed the production of CINC by cultured mesangial cells (Wu, X., and J. B. Lefkowith, unpublished observations ).

The data also suggest that the expression of CINC is a function of the expression of the cytokines, TNF- $\alpha$ and IL- $1 \beta$, in that both of these cytokines are upregulated in the context of nephritis, and prior work has shown that both of these cytokines can induce CINC in vitro $(11,20)$. The regulation of TNF- $\alpha$ production, though, appears distinct from that of CINC. Unlike CINC, TNF- $\alpha$ production was partly complement dependent and largely leukocyte dependent. These data suggest that TNF- $\alpha$ is derived from leukocytes (resident and elicited) stimulated both via the inciting antibody/immune complexes and the products of complement activation. Moreover, the lack of TNF$\alpha$ production by glomeruli from irradiated animals (which produce undiminished amounts of CINC) suggests that mechanisms other than TNF- $\alpha$ may be important in regulating CINC expression. Conjecturally, immune complexes or mesangial cell-derived IL-1 may stimulate CINC production by endogenous glomerular cells $(32,33)$.

A final point that the current data speak to is the relative role of CINC in mediating the influx of PMNs into a focus of tissue injury. In this study, we noted that anti-CINC antibodies attenuated the influx of PMNs, not as substantially as complement depletion (which completely prevents PMN influx; 18), but comparably to anti-TNF- $\alpha$ antibodies, soluble TNF receptor 1 , or anti-CD11/18 antibodies $(16,34)$. Also, we noted that CINC was produced by glomeruli from complement-depleted nephritic animals and glomeruli obtained $24 \mathrm{~h}$ after induction of nephritis, when PMN infiltration is substantially reduced (18, 35 ). These data suggest that CINC is engaged as a distal mechanism in the cascade of mediators controlling PMN trafficking into glomeruli. Moreover, they suggest that the production of CINC per se is not sufficient for PMN migration, but that it plays a contributory role in the context of the activation of other inflammatory mediators.

Based on the current study and other published work $(7,8$, $16-18,24,34,35$ ), we would propose the following paradigm for the cascade of events mediating the influx of PMNs into the glomerulus in the context of nephritis. The deposition of antibody/immune complexes in the glomerulus activates complement. Both antibody and complement together activate resident macrophages via $\mathrm{Fc}$ and complement receptors to express the cytokines IL- $1 \beta$ and TNF- $\alpha$. These cytokines then serve both to upregulate endothelial adhesiveness and to lead to the production of the chemokine, CINC, by endogenous glomerular cells (e.g., mesangial cells). Additional TNF- $\alpha$-independent mechanisms to activate CINC expression may also exist. Complement activation products, CINC, and the upregulation of endothelial adhesiveness are integrated to produce the initial PMN influx and activation. Efficient PMN emigration from the vasculature, however, requires a cooperative interaction with platelets. Lipid mediators, such as leukotriene $B_{4}$, appear to act as secondary positive feedback loops, which are called into play only with more substantial inflammation.

In summary, the current study serves to establish the importance of the chemokine, CINC, in rat immune complex-mediated inflammation and provide insights into the mechanisms underlying its synthesis and its relative role in the inflammatory cascade. These studies by implication suggest that human CXC chemokine homologues, IL-8 and the GRO family of polypeptides, may be similarly important in immune complex injury in man. Hopefully, developing an understanding of the role of chemokines in immune complex-mediated tissue damage will lead to pharmacologic strategies to manipulate immune complex-mediated tissue dysfunction, such as lupus nephritis, in man.

\section{Acknowledgments}

The authors gratefully acknowledge the review and comments of Drs. V. Michael Holers, Julian Ambrus, and Eric J. Brown.

This work was supported by National Institutes of Health grant DK37879. Dr. Lef kowith is a Burroughs-Wellcome Scholar in Clinical Pharmacology.

\section{References}

1. Oppenheim, J. J., C. O. Zachariae, N. Mukaida, and K. Matsushima. 1991. Properties of the novel proinflammatory supergene "intercrine"' cytokine family. Annu. Rev. Immunol. 9:617-648.

2. Miller, M. D., and M. S. Krangel. 1992. Biology and biochemistry of the chemokines: a family of chemotactic and inflammatory cytokines. Crit. Rev. Immunol. 12:17-46.

3. Koch, A. E., P. J. Polverini, S. L. Kunkel, L. A. Harlow, L. A. DiPietro, V. M. Elner, S. G. Elner, and R. M. Strieter. 1992. Interleukin-8 as a macrophagederived mediator of angiogenesis. Science (Wash. DC). 258:1798-1801.

4. Taub, D. D., K. Conlon, A. R. Lloyd, J. J. Oppenheim, and D. J. Kelvin. 1993. Preferential migration of activated CD4+ and CD8 + T-cells in response to MIP-1-alpha and MIP-1-beta. Science (Wash. DC). 260:355-358.

5. Gimbrone, M. A., M. S. Obin, A. F. Brock, E. A. Luis, P. E. Hass, C. A. Hebert, Y. K. Yip, D. W. Leung, D. G. Lowe, W. J. Kohr, W. C. Darbonne, K. B. Bechtol, and J. B. Baker. 1989. Endothelial interleukin 8: a novel inhibitor of leukocyte-endothelial interactions. Science (Wash. DC). 246:1601-1603.

6. Hechman, D. H., M. I. Cybalsky, J. B. Baker, and M. A. Gimbrone. 1990 Intravenous endothelial IL-8 reduces neutrophil accumulation at intradermal sites of inflammation. FASEB (Fed. Am. Soc. Exp. Biol.) J. 4:890a (Abstr.).

7. Couser, W. G. 1990. Mediation of immune glomerular injury. J. Am. Soc. Nephrol. 1:13-29.

8. Couser, W. G. 1993. Pathogenesis of glomerulonephritis. Kidney Int. 44:S19-S26.

9. Watanabe, K., F. Koizumi, Y. Kurashige, S. Tsurufuji, and H. Nakagawa. 1991. Rat CINC, a member of the interleukin-8 family, is a neutrophil-specific chemoattractant in vivo. Exp. Mol. Pathol. 55:30-37.

10. Iida, M., K. Watanabe, M. Tsurufuji, K. Takaishi, Y. Iizuka, and S Tsurufuji. 1992. Level of neutrophil chemotactic factor CINC/gro, a member of the interleukin- 8 family, associated with lipopolysaccharide-induced inflammation in rats. Infect. Immun. 60:1268-1272.

11. Zagorski, J., and J. E. De Larco. 1993. Rat CINC (cytokine-induced neutrophil chemoattractant) is the homolog of the human GRO proteins but is encoded by a single gene. Biochem. Biophys. Res. Commun. 190:104-110.

12. Watanabe, K., S. Kinoshita, and H. Nakagawa. 1989. Purification and characterization of cytokine-induced neutrophil chemoattractant produced by epithelioid cell line of normal rat kidney (NRK-52E cell). Biochem. Biophys. Res. Commun. 161:1093-1099.

13. Camussi, G., C. Tetta, F. Bussolino, E. Turello, S. J. Brentjens, G. Montrucchi, and G. Andres. 1990. Effect of leukocyte stimulation on rabbit immune complex glomerulonephritis. Kidney Int. 38:1047-1055.

14. Brennan, D. L., M. Yui, R. Wuthrich, and V. Kelley. 1989. Tumor necrosis factor and IL-1 in New Zealand black/white mice: enhanced gene expression and acceleration of renal injury. J. Immunol. 143:3430-3475.

15. Tomosugi, N. I., S. J. Cashman, H. Hay, C. D. Pusey, D. J. Evan, A. Shaw, and A. J. Rees. 1989. Modulation of antibody-mediated glomerular injury in vivo by bacterial lipopolysaccharide, tumor necrosis factor and IL-1. J. Immunol. 142:3083-3090.

16. Mulligan, M. S., K. J. Johnson, R. F. Todd, T. B. Issekutz, M. Miyasaka, T. Tamatani, C. W. Smith, D. C. Anderson, and P. A. Ward. 1993. Requirements for leukocyte adhesion molecules in nephrotoxic nephritis. J. Clin. Invest. 91:577587.

17. Tang, W. W., L. 1. Feng, J. L. Vannice, and C. B. Wilson. 1994. Interleukin-1 receptor antagonist ameliorates experimental anti-glomerular basement membrane antibody-associated glomerulonephritis. J. Clin. Invest. 93:273-279.

18. Lefkowith, J. B., T. Nagamatsu, J. Pippin, and G. F. Schreiner. 1991. 
Role of leukocytes in metabolic and functional derangements of experimental glomerulonephritis. Am. J. Physiol. 261:F213-F220.

19. Bradley, P. P., D. A. Priebat, R. D. Christensen, and G. Rothstein. 1982 Measurement of cutaneous inflammation: estimation of neutrophil content with an enzyme marker. J. Invest. Derm. 78:206-209.

20. Wittwer, A. J., L. S. Carr, J. Zagorski, G. J. Dolecki, B. A. Crippes, and J. E. De Larco. 1993. High-level expression of cytokine-induced neutrophil chemoattractant (CINC) by a metastatic rat cell line: purification and production of blocking antibodies. J. Cell Physiol. 156:421-427.

21. Mulligan, M. S., M. L. Jones, M. A. Bolanowski, M. P. Baganoff, C. L. Deppeler, D. M. Meyers, U. S. Ryan, and P. A. Ward. 1993. Inhibition of lung inflammatory reactions in rats by an anti-human IL-8 antibody. J. Immunol. 150:5585-5595.

22. Driscoll, K. E., D. G. Hassenbein, J. Carter, J. Poynter, T. N. Asquith, R. A Grant, J. Whitten, M. P. Purdon, and R. Takigiku. 1993. Macrophage inflammatory proteins 1 and 2: expression by rat alveolar macrophages, fibroblasts, and epithelia cells and in rat lung after mineral dust exposure. Am. J. Resp. Cell Mol. Biol. 8:311-318.

23. Tisher, C. C., and K. M. Madsen. 1986. Anatomy of the kidney. In The Kidney. B. M. Brenner and F. C. Rector, editors. W. B. Saunders Co., Philadelphia. 3-60.

24. Wu, X., J. Pippin, and J. B. Lefkowith. 1993. Platelets and neutrophils are critical to the enhanced glomerular arachidonate metabolism in acute nephrotoxic nephritis in rats. J. Clin. Invest. 91:766-773.

25. Nagamatsu, T., J. Pippin, G. F. Schreiner, and J. B. Lefkowith. 1992 Paradoxical exacerbation of leukocyte-mediated glomerulonephritis with cyclooxygenase inhibition. Am. J. Physiol. 263:F228-F236.

26. Davis, L. B., M. D. Dibner, and J. F. Battey. 1986. Basic Methods in Molecular Biology. Elsevier Science Publishing Co. Inc., New York. 130 pp.

27. Crippes, B. A., J. Zagorski, L. S. Carr, A. J. Wittwer, G. J. Dolecki, and J. E. De Larco. 1993. Investigation of possible autocrine functions for rat GRO/
CINC (cytokine-induced neutrophil chemoattractant). J. Cell Physiol. 156:412420.

28. Schreiner, G. F., J. M. Kiely, R. S. Cotran, and E. R. Unanue. 1981. Characterization of resident glomerular cells in the rat expression la determinants and manifesting genetically restricted interactions with lymphocytes. J. Clin. Invest. 68:920-931.

29. Watanabe, K., K. Konishi, M. Fujioka, S. Kinoshita, and H. Nakagawa. 1989. The neutrophil chemoattractant produced by the rat kidney epithelioid cell line NRK-52E is a protein related to the $\mathrm{KC} /$ gro protein. J. Biol. Chem. 264:19559-19563.

30. Sekido, N., N. Mukaida, A. Harada, I. Nakanishi, Y. Watanabe, and K. Matsushima. 1993. Prevention of lung reperfusion injury in rabbits by a monoclonal antibody against interleukin-8. Nature (Lond.). 365:654-657.

31. Blackham, A., A. A. Norris, and F. A. M. Woods. 1985. Models for evaluating the anti-inflammatory effects of inhibitors of arachidonic acid metabolism. J. Pharm. Pharmacol. 37:787-793.

32. Satriano, J. A., M. Shuldiner, K. Hora, Y. Xing, Z. Shan, and D. Schlondorff. 1993. Oxygen radicals as second messengers for expression of the monocyte chemoattractant protein, JE/MCP-1, and the monocyte colony-stimulating factor, CSF-1, in response to tumor necrosis factor-alpha and immunoglobulin-g-evidence for involvement of reduced nicotinamide adenine dinucleotide phosphate (NADPH)-dependent oxidase. J. Clin. Invest. 92:1564-1571.

33. Werber, H. I., S. N. Emancipator, M. L. Tykocinski, and J. R. Sedor. 1987. The interleukin 1 gene is expressed by rat glomerular mesangial cells and is augmented in immune complex glomerulonephritis. J. Immunol. 138:32073212 .

34. Wu, X., J. Pippin, and J. B. Lefkowith. 1993. Attenuation of immunemediated glomerulonephritis with an anti-CD11b monoclonal antibody. Am. J. Physiol. 264:F715-F721.

35. Lefkowith, J. B., J. Pippin, T. Nagamatsu, and V. Lee. 1992. Urinary eicosanoids and the assessment of glomerular inflammation. J. Am. Soc. Nephrol. 2:1560-1567. 